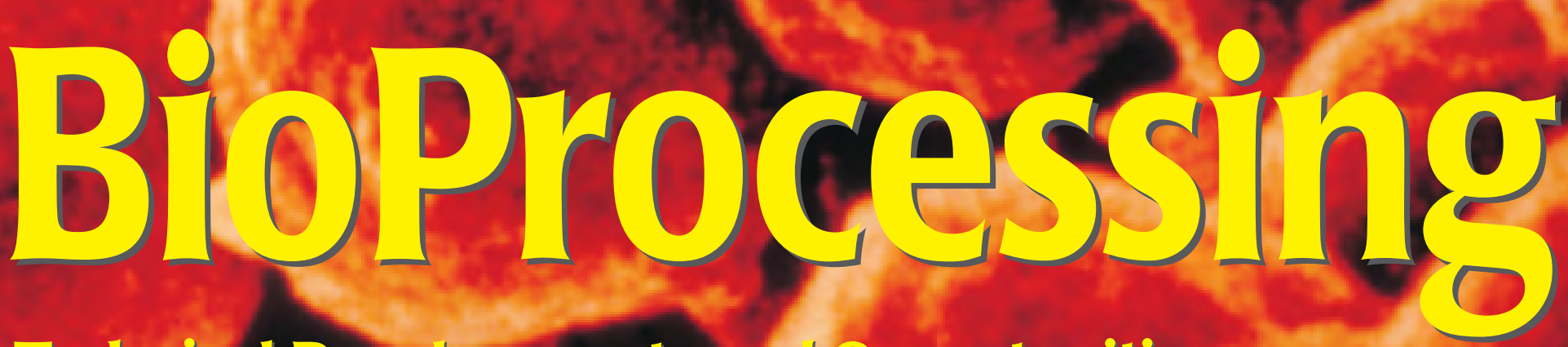

Technical Developments ans.| Opportunities 


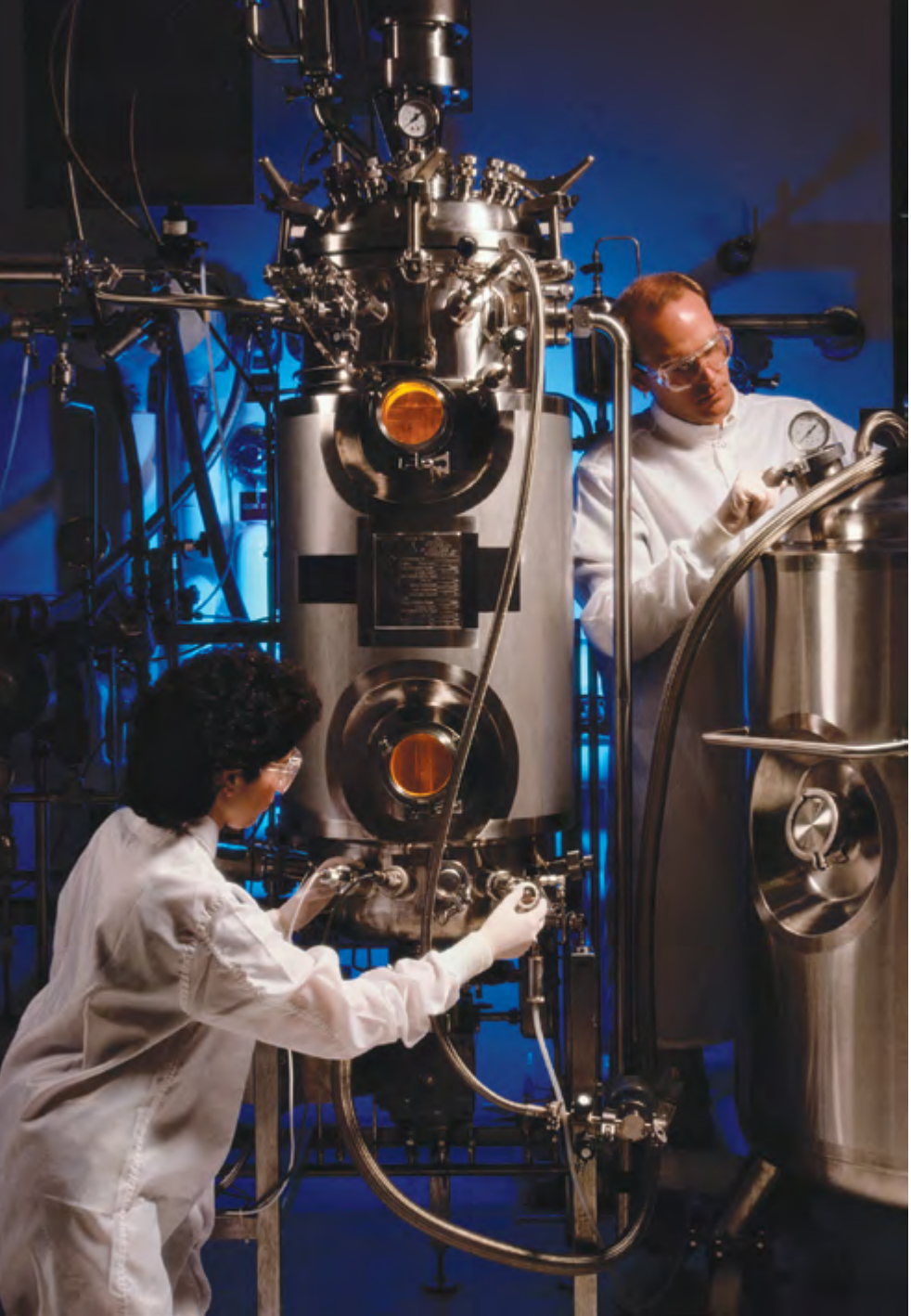


Figure 1. Manufacturing Facility Timeline

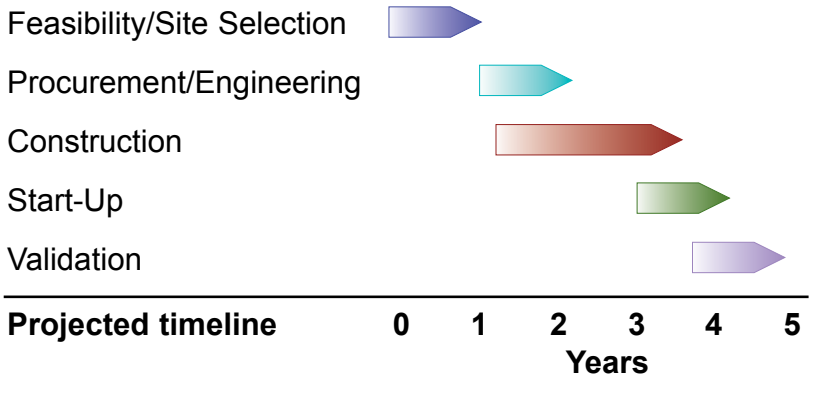

Source: U.S. Bancorp Piper Jaffray, IDEC Pharmaceuticals, Biogen.

Combined, these products generated $\$ 7.3$ billion in sales, or $68 \%$ of non-antibody protein sales in 2000 .

While monoclonal antibodies and antibody fusion proteins made up only $20 \%$ of biologics sales in 2000 , this segment is growing more rapidly than biologics in total. Specifically, these products generated approximately $\$ 2.6$ billion of sales in 2000, compared to \$1.8 billion in 1999. Genentech/IDEC's Rituxan was the leading monoclonal antibody in 2000, generating $\$ 427$ million in sales, while Immunex's ENBREL was the top-selling fusion protein, with $\$ 652$ million in sales that year.

We estimate that all protein-based therapeutics utilized approximately 298,000 liters of bioreactor capacity in the year 2000 , which accounts for roughly three-quarters of current industry capacity of 413,000 liters. Moreover, according to our estimates, monoclonal antibodies and ENBREL required about 98,000 liters of bioreactor capacity, or approximately one-quarter of the total available capacity. ENBREL, although not a monoclonal antibody, is composed of a soluble receptor fused to an antibody portion that makes its manufacturing capacity requirements (on a kilogram basis) and dosing regimen similar to that of antibodies. Due to new approvals and

Figure 2. Cost Breakdown of New Facility

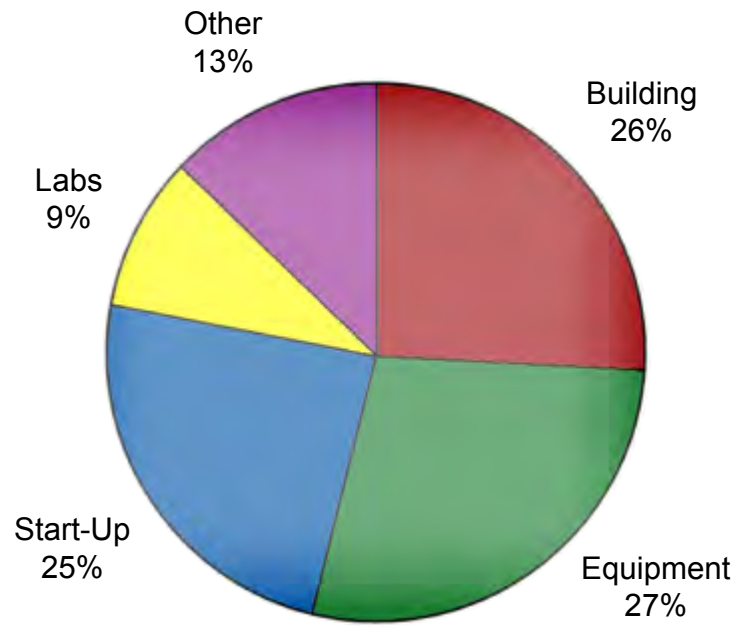

Source: IDEC Pharmaceuticals, U.S. Bancorp Piper Jaffray estimates increasing demand for existing marketed biologics, we believe that by the end of 2001 biologics manufacturing facilities were operating at, or near, full industry capacity.

\section{The Growing Pipeline}

Based on the successes of biologics such as Amgen's Epogen and Neupogen, Biogen's Avonex, Genentech/IDEC's Rituxan and Immunex's ENBREL, large pharmaceutical companies that traditionally avoided large molecule drugs are now seeking to develop such therapies and new biotech companies are opening their doors at an amazing pace. This unprecedented interest in new proteins and antibodies stems from their potential to target a variety of diseases in a very specific manner, thus maximizing efficacy while minimizing side effects. Potential disease targets include major therapeutic classes such as cancer, inflammatory disease, cardiovascular, and infectious diseases.

According to our research, there are currently 21 Phase III and 39 Phase II monoclonal antibodies, fusion proteins, and antibody fragments in development. Assuming a $50 \%$ success rate for the Phase III candidates and a 25\% success rate for the Phase II candidates, and including Campath, we estimate there will be 21 new antibodies reaching the market by the year 2005.

Additionally, we estimate that there are currently 18 Phase III and 21 Phase II non-antibody protein therapeutics in development. Again assuming a 50\% success rate for the Phase III candidates and a $25 \%$ success rate for the Phase II candidates, we project there will be 19 new non-antibody protein therapeutics reaching the market by 2005 .

\section{An Emerging Issue}

In recent years, there have been several high profile cases of biotech companies stumbling because of insufficient manufacturing resources at their disposal. With the growing and advanced pipeline of biologic drugs in the biotech industry, manufacturing is becoming even more important, as is evident from several recent deals and alliances.

The recent supply transfer agreement between MedImmune and Immunex clearly underscores the challenges Immunex is facing in manufacturing ENBREL to meet demand. Under this agreement, MedImmune will receive payments from Immunex to release Synagis manufacturing slots at contract manufacturer Boehringer-Ingelheim for the production of Immunex's ENBREL.

However, even having available manufacturing capacity does not necessarily guarantee that production will proceed as planned. Two companies producing pegylated interferonsSchering-Plough and Roche-are both experiencing supply issues. The launch of Roche's drug, Pegasys, originally planned for the fourth quarter of 2001, is now expected to occur in the second half of 2002 due to unforeseen changes in manufacturing required to scale up the production of the drug. More recently, concerns over Schering-Plough's recently approved drug PEG-Intron have surfaced. The company is requiring patients to receive a patient number for drug allocation, leading some to question if demand can be met this year. 
Similarly, the BLA filing and launch of Genentech and XOMA's Xanelim for psoriasis was unexpectedly pushed back recently when the companies announced that the FDA would require additional pharmacokinetics testing in healthy volunteers. This study is required because minor manufacturing modifications were made during Phase III trials to allow for large-scale production of Xanelim.

Other companies have opted, at least for now, to outsource their manufacturing requirements. ImClone, Celltech Group, and Genzyme Transgenics all contracted with Lonza Biologics to meet their manufacturing needs. These biotechnology companies are not alone. Eli Lilly, more than four years ago, called on Lonza to manufacture its recently approved severe sepsis drug, Xigris.

\section{Building a New Facility}

Building a new biologics manufacturing facility requires long lead times (see Figure 1) and heavy fixed costs. Industry sources estimate that it can take three to five years to build a new biologics manufacturing facility, starting from the initial steps of feasibility studies and site selection to engineering design, construction, start-up, and operations. Estimated costs for a largescale, new biologics facility with a total bioreactor capacity of roughly 100,000 liters range from $\$ 200$ to $\$ 400$ million (see Figure 2 for cost breakdown).

\section{Current and Future Capacity}

Since May 2001, we have held discussions with more than a dozen leading biotech companies to estimate the current and future (2005/2006) biologics manufacturing capacity. Table 1 lists the capacity in terms of fermentation reac- tor volume, assuming a batch process. We estimate that the current manufacturing capacity is about 413,000 liters and that an additional 938,000 liters of capacity that is being built will come on line in the next four to five years.

The bulk of this new capacity is being built by American Home Products/Immunex, Boehringer-Ingelheim, Biogen, Genentech and IDEC Pharmaceuticals. We estimate that only four biopharmaceutical companies, Amgen, Biogen, Boehringer-Ingelheim, and Genentech, will control more than half of the world's biologics production capacity by mid-decade.

\section{Can Capacity Match Demand?}

The answer, according to our analysis, is surprisingly "yes." For several years, many industry observers have expressed concern that, with all the new biologics expected to reach the market between now and mid-decade, there would not be enough production capacity available. Our analysis indicates that there will be more than enough capacity available in the 2005/2006 time frame.

Specifically, by mid-decade, we expect industry capacity to reach 1.4 million liters, while only 0.9 million liters capacity will be required for commercialized products. (Some additional capacity will be utilized for products in clinical trials, but we still believe that significant excess capacity will exist.) In fact, excess capacity is likely to be even larger due to production efficiencies that we and the manufacturers expect will occur-but to be conservative, we have assumed that production processes in the middle of the decade will be only as efficient as they are now.

Our analysis takes into account an estimated 15\% annual sales growth for
Table 1. Biologics Manufacturing Capacity

\begin{tabular}{|lcc|c|}
\hline & $\begin{array}{c}\text { Current } \\
\text { Manufacturing } \\
\text { Volume (L) }\end{array}$ & $\begin{array}{c}\text { Additional } \\
\text { Manufacturing } \\
\text { Volume (L) }\end{array}$ & $\begin{array}{c}\text { Total } \\
\text { Capacity } \\
\mathbf{2 0 0 5}\end{array}$ \\
\hline Contractors subtotal & 122,400 & 133,500 & 255,900 \\
\hline Drug/Biotech companies subtotal & 291,071 & 804,912 & $1,095,483$ \\
\hline Total Industry capacity & $\mathbf{4 1 3 , 4 7 1}$ & $\mathbf{9 3 7 , 9 1 2}$ & $\mathbf{1 , 3 5 1 , 3 8 3}$ \\
\hline
\end{tabular}

Source: Company reports, private discussions with companies, U.S. Bancorp Piper Jaffray estimates large molecule therapeutics currently on the market, as well as the 40 new large molecule therapeutics (including the six approved in 2001) that are expected to reach the market in the next few years, as described earlier.

As we have said, the bulk of the manufacturing capacity will be at a handful of companies, most of which are not contract manufacturers. As a result, biotech companies that do not have either in-house manufacturing capacity or long-term contracts/partnerships with those that do, will be in a difficult position.

Peter L. Ginsberg is senior research analyst, Sandeep Bhatia, Ph.D. and Rachel L. McMinn, Ph.D. are research analysts at U.S. Bancorp Piper Jaffray, Minneapolis, MN 55402, www.gotoanalysts.com. Contact Susan Filkins for more information,SFilkins@pjc.com.

U.S. Bancorp Piper Jaffray (USBPJ) makes a market in the following securities that are mentioned in this article:

American Home Products, Amgen, Biogen, Eli Lilly, Genentech, IDEC Pharmaceuticals, Immunex, Johnson \& Johnson, Medlmmune, Schering Plough, and Xoma.

Nondeposit investment products are not insured by the FDIC, are not deposits or other obligations of or guaranteed by U.S. Bank National Association or its affiliates, and involve investment risks, including possible loss of the principal amount invested.

This material is based on data obtained from sources we deem to be reliable; it is not guaranteed as to accuracy and does not purport to be complete. This information is not intended to be used as the primary basis of investment decisions. Because of individual client requirements, it should not be construed as advice designed to meet the particular investment needs of any investor. It is not a representation by us or an offer or the solicitation of an offer to sell or buy any security. Further, a security described in this release may not be eligible for solicitation in the states in which the client resides. U.S. Bancorp and its affiliated companies, and their respective officers or employees, or members of their families, may have a beneficial interest in the company's securities and may purchase or sell such positions in the open market or otherwise. This report is a communication made in the United Kingdom by U.S. Bancorp Piper Jaffray to market counterparties or intermediate customers and is exclusively directed at such persons; it is not directed at private customers and any investment or services to which the communication may relate will not be available to private customers. In the United Kingdom, no persons other than a market counterparty or an intermediate customer should read or rely on any of the information in this communication. Securities products and services offered through U.S. Bancorp Piper Jaffray, member SIPC and NYSE, Inc., a subsidiary of U.S. Bancorp. Gotoanalysts.com

(C) 2002 U.S. Bancorp Piper Jaffray 